\title{
The Prevalence of Celiac Disease in a Fracture Liaison Service Population
}

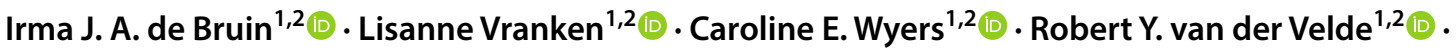

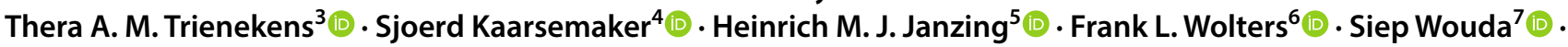 \\ Piet P. M. M. Geusens $s^{8,9}$. Joop P. W. van den Bergh ${ }^{1,2,9}$
}

Received: 13 May 2020 / Accepted: 8 July 2020 / Published online: 28 July 2020

(c) The Author(s) 2020

\begin{abstract}
Celiac disease $(\mathrm{CD})$ is a known risk factor for osteoporosis and fractures. The prevalence of CD in patients with a recent fracture is unknown. We therefore systematically screened patients at a fracture liaison service (FLS) to study the prevalence of $\mathrm{CD}$. Patients with a recent fracture aged $\geq 50$ years were invited to VieCuri Medical Center's FLS. In FLS attendees, bone mineral density (BMD) and laboratory evaluation for metabolic bone disorders and serological screening for CD was systematically evaluated. If serologic testing for $\mathrm{CD}$ was positive, duodenal biopsies were performed to confirm the diagnosis CD. Data were collected in 1042 consecutive FLS attendees. Median age was 66 years (Interquartile range (IQR) 15), 27.6\% had a major and $6.9 \%$ a hip fracture, $26.4 \%$ had osteoporosis and $50.8 \%$ osteopenia. Prevalent vertebral fractures were found in $29.1 \%$. CD was already diagnosed in two patients $(0.19 \%)$, one still had a positive serology. Three other patients $(0.29 \%)$ had a positive serology for $\mathrm{CD}$ (one with gastro-intestinal complaints). In two of them, $\mathrm{CD}$ was confirmed by duodenal histology $(0.19 \%)$ and one refused further evaluation. The prevalence of biopsy-proven CD was therefore $0.38 \%(4 / 1042)$ of which $0.19 \%$ (2/1042) was newly diagnosed. The prevalence of CD in patients with a recent fracture at the FLS was $0.38 \%$ and within the range of reported prevalences in the Western-European population (0.33-1.5\%). Newly diagnosed CD was only found in $0.19 \%$. Therefore, standard screening for CD in FLS patients is not recommended.
\end{abstract}

Keywords Fracture liaison service $\cdot$ Celiac disease $\cdot$ Osteoporosis $\cdot$ Fractures

\section{Introduction}

Celiac disease (CD) is an autoimmune enteropathy induced by dietary proteins in wheat, rye, and barley. The presentation of symptoms widely varies. In 2012, the following
Oslo definitions for $\mathrm{CD}$ were stated: 'classical $\mathrm{CD}$ presents with signs and symptoms of malabsorption. Besides malabsorption, other symptoms of diarrhea, steatorrhea, weight loss, or growth failure are required. Non-classical CD presents with gastro-intestinal symptoms and extra intestinal
Joop P. W. van den Bergh

jvdbergh@viecuri.nl

1 Department of Internal Medicine, VieCuri Medical Center, Tegelseweg 210, PO Box 1926, 5900 BX Venlo, The Netherlands

2 NUTRIM School of Nutrition and Translational Research in Metabolism, Department of Internal Medicine, Maastricht University Medical Centre+ (MUMC+), PO Box 616, 6200 MD Maastricht, The Netherlands

3 Department of Medical Microbiology, VieCuri Medical Center, Venlo, The Netherlands

4 Department of Orthopaedic Surgery, VieCuri Medical Center, Venlo, The Netherlands
5 Department of Surgery, VieCuri Medical Center, Venlo, The Netherlands

6 Department of Gastro-Enterology, VieCuri Medical Center, Venlo, The Netherlands

7 Department of Pathology, VieCuri Medical Center, Venlo, The Netherlands

8 Department of Internal Medicine, Subdivision Rheumatology, CAPHRI, Maastricht University Medical Centre+ (MUMC+), PO Box 616, 6200 MD Maastricht, The Netherlands

9 Biomedical Research Centre, Hasselt University, Agoralaangebouw D, 3590 Diepenbeek, Belgium 
manifestations, but without signs and symptoms of malabsorption and diarrhea. Subclinical CD is disease below the threshold of clinical detection without signs or symptoms sufficient to trigger $\mathrm{CD}$ testing in routine practice' [1]. It was demonstrated that in a period of 15 years (1998-2012) an increasing part of the $\mathrm{CD}$ patients had a subclinical $\mathrm{CD}$ or a non-classical phenotype instead of the classical CD phenotype [2].

$\mathrm{CD}$ is a known risk factor for osteoporosis and fractures, with a RR of 1.3-1.9 for fractures [3-6]. Malabsorption of calcium and vitamin $\mathrm{D}$ deficiency leads to secondary hyperparathyroidism. General malnutrition and underweight also result in a reduced bone mineral density (BMD) [3, 7]. Further, hypogonadism associated with $\mathrm{CD}$ might also affect bone metabolism [7, 8]. Chronic inflammation and release of proinflammatory cytokines lead to an increase in osteoclastic bone resorption [9]. Appropriate treatment of CD relieves symptoms and can improve BMD [10-12]. However, after diagnosis of $\mathrm{CD}$ the increased risk of fractures persists [6]. It was demonstrated that the increased fracture risk remained 20 years after diagnosis of CD [13].

The worldwide prevalence of $\mathrm{CD}$ based on serologic tests is reported to be $1.4 \%$ and of biopsy-proven CD $0.7 \%$ [14]. In the general unselected Northern American and WesternEuropean populations, the prevalence of $\mathrm{CD}$ is close to $1 \%$ and in Northern European countries it is slightly higher, around 1-1.5\% [15]. Rostami et al. reported a prevalence of biopsy-proven CD of 3 per 1000 persons in a Dutch population of healthy blood donors [16]. In high-risk populations, such as in type 1 diabetes patients and first-degree relatives of patients with $\mathrm{CD}$, the prevalence of $\mathrm{CD}$ is estimated to be higher than in the general population: 3-6\% in patients with type 1 diabetes and up to $20 \%$ in first-degree relatives of CD patients [15]. Based on a clinical review the prevalence of $\mathrm{CD}$ was estimated between 2 and 3\% in low-BMD populations [17]. A recent meta-analysis showed a prevalence of biopsy-proven $\mathrm{CD}$ of $1.6 \%$ in patients with osteoporosis [18].

From 1999 onwards, fracture liaison services (FLSs) were initiated aiming at reduction of subsequent fracture risk in high-risk patients, namely those who sustained a recent fracture $[19,20]$. Besides screening for osteoporosis, screening for metabolic bone disorders is recommended in FLS patients [21-24]. In general, laboratory evaluation of secondary causes of osteoporosis and metabolic bone disorders does not include screening for CD. Rios et al. concluded that there is no evidence for routine screening for $\mathrm{CD}$ in all patients with low BMD [17].

To our knowledge, the prevalence of CD in an FLS population has not been studied so far. This might be important, given the fact that $\mathrm{CD}$ is associated with increased fracture risk $[6,13]$. Therefore, our aim was to study the prevalence of $\mathrm{CD}$ in an FLS population. In view of the increased risk of fractures in $\mathrm{CD}$, we hypothesized that $\mathrm{CD}$ would be more frequent in the FLS population than the reported prevalence in the total population.

\section{Methods}

\section{Fracture Liaison Service}

We conducted a retrospective cohort study in patients with a recent clinical fracture, aged 50-90 years, visiting the FLS of a regional teaching hospital for fracture risk evaluation (VieCuri Medical Centre, Venlo, The Netherlands). Patients with a skull fracture, patients older than 90 years and patients with an active malignancy were excluded.

FLS attendees received a detailed questionnaire for evaluation of clinical risk factors for fractures, medical history, medication, previous fractures, and calcium intake and were scheduled for dual X-ray absorptiometry (DXA) measurement and a blood test. A visit at the outpatient clinic was scheduled after completion of these tests. At this visit height and weight were assessed, the questionnaire was evaluated and additional questions were asked. If laboratory results were abnormal, additional investigations were performed for detailed evaluation of newly diagnosed disorders when necessary. Depending on the BMD results, calcium intake and serum 25 -hydroxyvitamin $\mathrm{D}[25(\mathrm{OH}) \mathrm{D}]$ levels, patients were treated with calcium and vitamin D supplements, and anti-osteoporosis medication according to the Dutch guidelines for treatment of osteoporosis [25].

Index fractures were classified according to the Center classification: hip, major (vertebra, pelvis, distal femur, proximal tibia, multiple rib, and proximal humerus), minor (all others except major and finger $\&$ toe fractures), and finger \& toe fractures [26].

\section{DXA and VFA}

BMD in the left or right hip and the lumbar spine was determined using dual-energy X-ray absorptiometry (DXA) with the Hologic QDR 4500 (Hologic, Bedford, MA, USA). Diagnosis of osteoporosis was based on the World Health Organization criteria for BMD [27], as provided by the manufacturer for women and men and which are based on the National Health and Nutrition Examination Survey III database. T-score calculations were done for women with a female and for men with a male reference population, as provided by the manufacturer. Patients were classified according to the lowest value of T-score in total hip, femoral neck, or lumbar spine: osteoporosis as a T-score of -2.5 or less, osteopenia as a T-score between -2.5 and -1.0 , and normal $\mathrm{BMD}$ as a $\mathrm{T}$-score of -1.0 or higher. 
Assessment of vertebral fractures was performed via vertebral fracture assessment (VFA). Vertebral fractures were graded according to the grading of Genant et al. as grade $1,20-24 \%$ reduction in vertebral body height at the anterior, mid, or posterior location; grade 2, 25-39\%; or grade $3, \geq 40 \%$ reduction, respectively [28].

\section{Screening and Diagnosis of Celiac Disease}

In accordance with the Dutch and American guidelines of $\mathrm{CD}$, as first-line test the serological screening for $\mathrm{CD}$ was performed in this low-risk cohort [29, 30]. Serological screening consisted of measurement of serum IgA and IgA tissue transglutaminase antibodies (tTG). Serum IgA tTG values were measured using the ELiA Celikey IgA kit (Phadia AB, Uppsala, Sweden). The sensitivity and specificity for this test are $96 \%$ and $99 \%$, respectively. Anti-tTG $\operatorname{IgA}$ can only be assessed accurately if an IgA deficiency is excluded. Since IgA deficiency is more prevalent in patients with $\mathrm{CD}$ than in the general population, IgA was evaluated in all patients in addition to anti-tTG $\operatorname{Ig} \mathrm{A}$ [31]. If the $\operatorname{IgA}$ titer was less than $0.2 \mathrm{~g} / \mathrm{l}, \mathrm{IgG}$ tTG antibodies were measured. An anti-tTG IgA titer of $8 \mathrm{U} / \mathrm{ml}$ or more was considered as a positive test result suspicious for $\mathrm{CD}$. In patients with a positive anti-tTG IgA test, without a history of positive CD serology, an additional anti-endomysial IgA (EMA) (SciMedX IFA, Libra Diagnostica) test was performed as confirmation test. The sensitivity and specificity for this test vary between $95-99 \%$ and $97-98 \%$, respectively.

In the case of positive anti-tTG and anti-EMA test result, patients were referred to the gastroenterologist for a duodenoscopy with duodenal biopsies. Histopathological examination was performed according to the Modified Marsh criteria $[32,33]$. This classification describes the histopathology of $\mathrm{CD}$, based on three aspects: microscopic enteritis (increased intraepithelial lymphocyte (IEL) count), crypt hyperplasia and villus atrophy.

$\mathrm{CD}$ was diagnosed in case of a positive anti-tTG IgA and anti-endomysial IgA serology in combination with a duodenal biopsy with characteristics of $\mathrm{CD}$ that conform to the Modified Marsh classification.

Since the positive serology for CD can normalize with a gluten-free diet, $\mathrm{CD}$ cannot be excluded with negative serology. In addition to the serology, we verified the past medical history. In the case of a positive medical history for celiac disease, the medical record of the patient was checked for positive serology and duodenal biopsies in the past.

\section{Statistics}

Data were analyzed using descriptive statistics (mean, median) by IBM SPSS statistics 24 .
This retrospective cohort study was approved by the medical research ethics committee of the Academic Hospital Maastricht/University Maastricht (METC 2020-1508).

\section{Results}

From a total of 2376 consecutive patients with a recent fracture who were invited at the FLS, 1042 patients (43.9\%) actually attended the FLS. All FLS attendees were screened for CD. As shown in Table 1, median age of the study population was 66.0 years (Interquartile range (IQR) 15) and 719 $(69.0 \%)$ were women. The majority $(54.4 \%)$ had a minor fracture, $27.6 \%$ a major fracture, $6.9 \%$ a hip fracture, and

Table 1 Baseline characteristics FLS population $(n=1042)$

\begin{tabular}{|c|c|}
\hline Age (years) & 66.0 (IQR 15) \\
\hline Gender ( $\%$ females) & $69.0 \%$ \\
\hline Length $(\mathrm{cm})^{\mathrm{a}}$ & 165.5 (IQR 12) \\
\hline Weight $(\mathrm{kg})^{\mathrm{a}}$ & 75.0 (IQR 19.7) \\
\hline BMI $\left(\mathrm{kg} / \mathrm{m}^{2}\right)^{\mathrm{a}}$ & 26.8 (IQR 6.2) \\
\hline \multicolumn{2}{|l|}{ Fracture (center) $(\%)$} \\
\hline Finger and toe & $11.0 \%$ \\
\hline Minor & $54.4 \%$ \\
\hline Major & $27.6 \%$ \\
\hline Hip & $6.9 \%$ \\
\hline \multicolumn{2}{|l|}{$\mathrm{BMD}^{\mathrm{b}}(\%)$} \\
\hline Normal BMD & $22.8 \%$ \\
\hline Osteopenia & $50.8 \%$ \\
\hline Osteoporosis & $26.4 \%$ \\
\hline \multicolumn{2}{|l|}{ Vertebral fractures $(\mathrm{VFA})^{\mathrm{c}}(\%)$} \\
\hline At least one grade 1,2 , or $3(\%)$ & $29.1 \%$ \\
\hline At least one grade 2 or $3(\%)$ & $18.2 \%$ \\
\hline Grade 1 & $15.1 \%$ \\
\hline Grade 2 & $13.8 \%$ \\
\hline Grade 3 & $6.5 \%$ \\
\hline Self-reported calcium intake $\mathrm{mg} /$ day $^{\mathrm{d}}$ & 780.0 (IQR 387.0) \\
\hline Calcium $(\mathrm{mmol} / \mathrm{l})$ & 2.42 (IQR 0.10) \\
\hline Phosphate (mmol/l) & 1.13 (IQR 0.22) \\
\hline Albumin (g/l) & 40 (IQR 4) \\
\hline PTH (pmol/l) & 5.3 (IQR 3.5) \\
\hline Hemoglobin (mmol/l) & 8.5 (IQR 0.9) \\
\hline $\operatorname{IgA}<0.2 \mathrm{~g} / 1(\%)$ & $0.19 \%$ \\
\hline Anti-tTG IgA > 8 U/ml (\%) & $0.38 \%$ \\
\hline Vitamin $\mathrm{D}<50 \mathrm{nmol} / \mathrm{l}$ & $40 \%$ \\
\hline \multicolumn{2}{|c|}{$\begin{array}{l}B M I \text { body mass index, } B M D \text { bone mineral density, } V F A \text { vertebral } \\
\text { fracture assessment, } P T H \text { parathyroid hormone, anti-tTG anti-tissue } \\
\text { transglutaminase }\end{array}$} \\
\hline \multicolumn{2}{|l|}{${ }^{\mathrm{a}}$ Data missing of 6 patients } \\
\hline \multicolumn{2}{|l|}{${ }^{\mathrm{b}}$ Data missing of 2 patients } \\
\hline \multicolumn{2}{|l|}{${ }^{\mathrm{c}}$ Data missing of 3 patients } \\
\hline${ }^{\mathrm{d}}$ Data missing of 22 patients & \\
\hline
\end{tabular}


$11 \%$ a finger or toe fracture. Osteoporosis was diagnosed in $26.4 \%$, osteopenia in $50.8 \%$, and $22.8 \%$ had a normal BMD. VFA analysis showed at least one prevalent vertebral fracture (at least one grade 1, 2, or 3) in 303 patients $(29.1 \%)$ and at least one grade 2 or 3 vertebral fracture in 190 patients $(18.2 \%)$. Vitamin D deficiency (serum $25(\mathrm{OH})$ $\mathrm{D}<50 \mathrm{nmol} / \mathrm{l}$ ) was present in $40 \%$. The median serum calcium (corrected for serum albumin) was $2.42 \mathrm{mmol} / \mathrm{l}$ (IQR 0.10). None of the patients had hypocalcemia (serum calcium corrected for albumin $<2.10 \mathrm{mmol} / \mathrm{l}$ ) and 69 patients had hypercalcemia with a corrected serum calcium of $>2.55 \mathrm{mmol} / \mathrm{l}$. The median parathyroid hormone (PTH) was $5.3 \mathrm{pmol} / \mathrm{l}$ (IQR 3.5) (reference range: $2.2-10.0 \mathrm{pmol} / \mathrm{l}$ ). The median hemoglobin was $8.5 \mathrm{mmol} / \mathrm{l}$ (IQR 0.9). In total, 75 patients had anemia, of which 35 men with a hemoglobin of $<8.0 \mathrm{mmol} / \mathrm{l}$, and 40 women with a hemoglobin of $<7.2 \mathrm{~mol} / \mathrm{l}$. The self-reported calcium intake was $780.0 \mathrm{mg}$ per day (IQR 387.0).

\section{Serologic Testing and Histopathological Testing for CD}

Two out of 1042 patients had IgA deficiency $(0.19 \%)$ and were further tested with anti-tTg IgG which was negative in both. Anti-tTG IgA serology was positive in $4(0.38 \%)$ patients (patient A-D, Table 2). In one patient with previously positive $\mathrm{CD}$ serology and biopsy-proven $\mathrm{CD}$, current anti-tTG IgA serology was negative (patient E, Table 2).

Table 2 Characteristics of the FLS patients with positive tTG serology or known celiac disease

\begin{tabular}{|c|c|c|c|c|c|}
\hline & Patient A & Patient B & Patient $\mathrm{C}$ & Patient D & Patient E \\
\hline Age & 64 & 50 & 68 & 76 & 60 \\
\hline Gender & Female & Female & Female & Male & Male \\
\hline Length (cm) & 163.3 & 162 & 164.6 & 178 & 183.5 \\
\hline Weight (kg) & 81.9 & 62.2 & 69.7 & 85 & 86 \\
\hline BMI & 30.71 & 23.7 & 25.73 & 26.83 & 25.54 \\
\hline Fracture (center) & Minor & Minor & Major & Minor & Minor \\
\hline Fracture location & Radial head & Distal radius & Tibial plateau & Tarsal bone & Midshaft ulnar \\
\hline \multicolumn{6}{|l|}{ BMD (T-scores) } \\
\hline Lumbar spine & -2.6 & -2.9 & -0.2 & -1.7 & -0.7 \\
\hline Femoral neck & -2.4 & -2.2 & -1.2 & -2.3 & -0.2 \\
\hline Total hip & -2.2 & -0.8 & -0.4 & -1.8 & 0 \\
\hline BMD & Osteoporosis & Osteoporosis & Osteopenia & Osteopenia & Normal BMD \\
\hline $\begin{array}{l}\text { Vertebral fractures } \\
\text { (VFA) }\end{array}$ & No VF & No VF & Th11 grade 1 & Th12 grade 3 & No VF \\
\hline $\begin{array}{l}\text { Self-reported calcium } \\
\text { intake } \mathrm{mg} / \text { day }\end{array}$ & 711 & 369 & 1169 & 1028 & 1020 \\
\hline Calcium (mmol/l) & 2.35 & 2.46 & 2.43 & 2.42 & 2.34 \\
\hline Phosphate (mmol/l) & 1.30 & 1.25 & 1.17 & 1.03 & 1.00 \\
\hline Albumin (g/l) & 39 & 41 & 38 & 34.0 & 41.0 \\
\hline $\begin{array}{l}\text { 25-OH vitamin D } \\
(\mathrm{nmol} / \mathrm{l})\end{array}$ & 75 & 101 & 29 & 83 & 60 \\
\hline PTH (pmol/l) & 4.4 & 4.0 & 7.8 & 18.0 & 5.0 \\
\hline Hemoglobin (mmol/l) & 7.4 & 8.0 & 8.3 & 8.2 & 8.8 \\
\hline $\operatorname{IgA}(g / l)$ & 6.38 & 2.72 & 2.14 & 4.03 & 4.43 \\
\hline IgA anti-tTG (U/ml) & 91.4 & 36.5 & 24.6 & 37.4 & 1.6 \\
\hline IgA anti-EMA & Positive & Positive & Positive & Not performed & Not performed \\
\hline \multirow[t]{2}{*}{ Duodenal biopsy } & - & Marsh 3c & Marsh 3a & Marsh 3b & Marsh 3b \\
\hline & Uncertain celiac disease & $\begin{array}{l}\text { Proven celiac disease } \\
\quad \text { (new) }\end{array}$ & $\begin{array}{l}\text { Proven celiac disease } \\
\quad \text { (new) }\end{array}$ & $\begin{array}{l}\text { Proven celiac disease } \\
\quad \text { (known) }\end{array}$ & $\begin{array}{l}\text { Proven celiac } \\
\text { disease } \\
\text { (known) }\end{array}$ \\
\hline Osteoporosis treatment & Refused treatment & Start alendronic acid & $\begin{array}{l}\text { No indication for treat- } \\
\text { ment }\end{array}$ & $\begin{array}{l}\text { Treated with risedronic } \\
\text { acid }\end{array}$ & $\begin{array}{l}\text { No indication } \\
\text { for treatment }\end{array}$ \\
\hline
\end{tabular}

$F L S$ fracture liaison service, $B M I$ body mass index, $B M D$ bone mineral density, $V F A$ vertebral fracture assessment, $P T H$ parathyroid hormone, $I g A$ Immunoglobulin A, $I g A$ anti-tTg anti-tissue transglutaminase antibodies, $I g A$ anti-EMA anti-endomysial antibodies 
Of the four patients with positive anti-tTG IgA serology, one patient was already diagnosed with biopsy-proven CD (patient D). The tTG titers varied between 1.6 and $91.4 \mathrm{U} /$ $\mathrm{ml}$ (normal range $<8.0 \mathrm{U} / \mathrm{ml}$ ). The three new patients with positive serology all had a positive IgA anti-EMA.

Based on the positive serology with an anti-t Tg IgA of $91.4 \mathrm{U} / \mathrm{ml}$ and positive anti-EMA IgA, patient A was suspected for having $\mathrm{CD}$, but she refused further examination and treatment. The two other new patients with positive serology were further evaluated by the gastroenterologist. Duodenal biopsies confirmed the diagnosis of CD in both patients (patients B and C) with biopsy results of Marsh $3 \mathrm{c}$ and $3 \mathrm{a}$ histology, respectively. Patients $\mathrm{D}$ and $\mathrm{E}$ with known CD had both previous biopsy results with Marsh $3 b$ histology. The prevalence of biopsy-proven CD in our FLS cohort was therefore $0.38 \%$ (4/1042), with newly diagnosed, biopsy-proven CD in 0.19\% (2/1042).

\section{Symptoms and Signs in CD Patients at the FLS}

At the outpatient clinic, only one patient (B) had gastrointestinal complaints, namely loose stools. In two patients, $\mathrm{CD}$ was diagnosed 3 and 9 years before the visit at the FLS, based on iron deficiency anemia in patient $\mathrm{D}$ and gastro-intestinal complaints in patient E. One patient (C) had a low vitamin $\mathrm{D}$, the others had a normal vitamin $\mathrm{D}$ level (reference range: $50-140 \mathrm{nmol} / \mathrm{l}$ ). In patient $\mathrm{D}$, the PTH was $18 \mathrm{pmol} / \mathrm{l}$ with normal calcium and vitamin D levels, which points at a secondary hyperparathyroidism possibly due to malabsorption. BMD was normal in one patient (Patient E), two patients had osteopenia (C and D), and two had osteoporosis (A and B). Prevalent VFs were found in two patients (one grade 1 vertebral fracture in patient $\mathrm{C}$ and one grade 3 vertebral fracture in patient $\mathrm{D}$ ).

\section{Treatment of CD and Osteoporosis}

Patient A refused treatment for $\mathrm{CD}$ and osteoporosis. Patients B and C started a gluten-free diet and patients $\mathrm{D}$ and $\mathrm{E}$ already had a gluten-free diet. All four patients (B-E) had regular visits at the outpatient clinic of the gastroenterologist. Treatment with oral bisphosphonates was started in patient B because of the diagnosis of osteoporosis after a recent major osteoporotic fracture at the distal radius, and patient $\mathrm{D}$ already received treatment with risedronic acid. Patients $\mathrm{C}$ and $\mathrm{E}$ did not receive antiosteoporosis treatment according to the Dutch guidelines (indication for treatment: T-score $<=-2.5$ and/or a moderate or severe vertebral fracture).

\section{Discussion}

In this cohort of 1042 consecutive FLS patients, four patients had biopsy-proven CD. In two patients, CD was already known $(0.19 \%)$ and in two patients $C D$ was newly detected $(0.19 \%)$ by systematic serologic testing. One patient was suspected of having CD but refused further analysis. Since we based the diagnosis of CD on wellestablished criteria of positive CD serology and abnormal duodenal histology $[34,35]$, the diagnosis of $C D$ could not be confirmed in the fifth patient.

The prevalence of CD in general unselected Western populations is close to $1 \%$ and in the general unselected Northern European populations it is approximately 1-1.5\% [15]. In a Dutch population of healthy blood donors, the reported prevalence of biopsy-proven CD was $0.33 \%$ [16]. The prevalence of $0.38 \%$ in our Dutch FLS cohort was somewhat lower than reported in the general Western population and in the same range as in the Dutch healthy blood donors, but it was lower than most of the reported prevalences of $C D$ in osteoporosis patients $[15,16]$. Studies of the prevalence of $\mathrm{CD}$ in populations with osteoporosis showed varying prevalences. Legroux-Gérot et al. did not demonstrate positive CD serology (anti-tTG) in a cohort of 140 patients with osteoporosis [36]. Nuti et al. found a positive CD serology in $24(9.4 \%)$ patients with osteoporosis, but only in 10 patients a biopsy was done to prove CD [37]. Gonzalez et al. reported a prevalence of biopsy-proven $\mathrm{CD}$ of $0.8 \%$ in osteoporosis patients which was demonstrated to be equal to the prevalence in the healthy population [38]. A recent meta-analysis reported a prevalence of biopsy-proven CD of $1.6 \%$ among 3188 individuals with osteoporosis [18]. These results of varying prevalences might be explained by the different populations and importantly also by the different screening tests which were used for the diagnosis of CD. Hill et al. described differences in sensitivity and specificity of the serological tests [39].

The prevalence of $\mathrm{CD}$ in patients with a recent fracture at the FLS has not been studied before. This might be important, given the fact that $\mathrm{CD}$ is associated with increased fracture risk $[6,13]$. Hjelle et al. studied the prevalence of CD in 400 patients aged 40 years or older with a distal radius or ankle fracture compared to community-based controls [40]. The diagnosis of $\mathrm{CD}$ was based on serological screening of anti-t $\operatorname{Tg} \operatorname{IgA}$ in combination with histology from duodenal biopsy or a previous diagnosis of CD. Three patients with a fracture had known CD and among all patients with a fracture, 10 had positive serological screening, and nine of them underwent duodenal biopsies. Six patients with a fracture were newly diagnosed with biopsy-proven CD (a prevalence of 1.5\%) and 
in total nine patients had CD, a prevalence of $2.25 \%$. In the control group of 197 patients, four had biopsy-proven $\mathrm{CD}(2.0 \%)$ and in one patient with positive serology no biopsy was performed. Serology was only positive in two controls because of the use of a gluten-free diet in three known CD patients [40]. In this study, in patients with a fracture a positive anti-t $\operatorname{Tg} \operatorname{IgA}$ was more prevalent than in controls, but the prevalence of biopsy-proven CD in the fracture cohort was comparable to the control cohort. Compared to our study, the prevalence of $\mathrm{CD}$ was higher, although it was only studied in patients with a distal radius and ankle fracture. In addition, the prevalence in the control group was higher than in the general Western population. The prevalence of CD in our Dutch FLS cohort was comparable to the reported prevalence of $\mathrm{CD}$ in healthy Dutch blood donors. Hence, based on the study of Hjelle et al. and our findings, the prevalence of $\mathrm{CD}$ is not higher compared to healthy subjects without fractures. Therefore, we do not recommend standard screening for $\mathrm{CD}$ in all patients with a recent fracture.

The two patients with known CD of our cohort had signs or symptoms of $\mathrm{CD}$, namely iron deficiency anemia and gastro-intestinal complaints at the time of the $\mathrm{CD}$ diagnosis years ago. The three patients with new positive serology were not clinically suspected and therefore did not present as the classical phenotype, but seemed to have a subclinical or non-classical CD. It has been demonstrated that in the past years an increasing part of the $\mathrm{CD}$ patients has a subclinical $\mathrm{CD}$ or a non-classical phenotype instead of the classical CD phenotype [2].

Larussa et al. reported that a low BMD was found in $38-72 \%$ of patients at time of diagnosis of $\mathrm{CD}$ and in 9-47\% of patients on a gluten-free diet [41]. In small a cohort patients aged $>65$ years with a new diagnosis of $\mathrm{CD}$, osteoporosis was found in $67 \%$ of men and $70 \%$ of the women [42]. Appropriate treatment of CD relieved symptoms and can improve BMD [10-12]. Improvement of BMD with a gluten-free diet could also be achieved in patients aged $>65$ years [42].

In our cohort, of the five with positive serology or biopsyproven $\mathrm{CD}$, two had osteoporosis (40\%), two had osteopenia (40\%), and one had a normal BMD. One patient had a major fracture at the tibia (patient $\mathrm{C}$ ). On the other hand, only $0.73 \%$ (2/275) of all patients with osteoporosis and only $0.35 \%(1 / 288)$ of all patients with a major fracture and $0.66 \%$ (2/303) of all patients with a prevalent vertebral fracture had CD. Therefore, fracture or BMD characteristics cannot be used to distinguish patients with possible $\mathrm{CD}$ from patients without $\mathrm{CD}$.

The cost of serologic CD screening (IgA and anti-tTG $\operatorname{IgA}$ ) at our hospital was $€ 22,42$ per patient and for the confirmation test (anti-endomysial IgA) $€ 32,41$. Given the low prevalence of CD in our FLS cohort, the number needed to screen in order to diagnose one patient with CD is 261 . In FLS patients with osteoporosis, the number needed to screen was 138 and in patients with a major osteoporotic fracture or a prevalent VF it was 288 and 152, respectively. Based on these findings, we believe screening for CD in FLS patients is not recommended, which is in line with Laszkowska et al. who also reported that routinely screening for $\mathrm{CD}$ in osteoporosis is not recommended because of the low prevalence of CD [18]. Nevertheless, it will be still indicated to analyze the presence of CD in FLS patients with laboratory results, comorbidity or symptoms suggestive of $\mathrm{CD}$. This is in line with the recommendation of Rios et al. of a targeted case finding approach [17]. Further, in younger patients with osteoporosis (aged $<50$ years) it is indicated to perform serological screening for $\mathrm{CD}$ because underlying causes of osteoporosis or metabolic bone diseases are more prevalent in these patients [43].

This study has several limitations. Approximately 50\% of invited patients with a recent fracture actually attended the FLS. It is therefore unknown whether the prevalence of CD in the attenders is comparable of those of the non-attenders. There might be a selection bias since patients with known CD will have standard DXA evaluations in the Netherlands according to the guidelines [29], which could have led to a higher proportion of CD patients in FLS non-attenders. Furthermore, one patient with positive serology refused further analysis for $\mathrm{CD}$. Therefore, it was not possible to confirm the positive serology with biopsies to diagnose $\mathrm{CD}$ properly. Thirdly, we did not check if patients were eating a gluten-free diet. The use of a gluten-free diet can normalize serology for $\mathrm{CD}$. Over the past years, there is an increase in people consuming a gluten-free diet. This increase can be explained partially because of people without $\mathrm{CD}$ avoiding gluten, for example as 'healthy' lifestyle [44, 45]. Fourthly, at our FLS there was no systematic evaluation of gastrointestinal symptoms and no standard evaluation of the family history of $\mathrm{CD}$. Therefore, we could not calculate the number needed to screen in FLS patients with gastro-intestinal complaints, nor could we calculate the number needed to screen in the high-risk patients with a first-degree relative with $\mathrm{CD}$. One of the strengths of this study was that serological screening consisted of measurement of serum $\operatorname{IgA}$ and $\operatorname{Ig} \mathrm{A}$ tissue transglutaminase antibodies (tTG) with a sensitivity and specificity for this test of $96 \%$ and $99 \%$, respectively. Further, this was the first study for CD screening in a general FLS population.

\section{Conclusion}

The prevalence of $\mathrm{CD}$ in patients with a recent fracture at the FLS was $0.38 \%$ and within the range of reported prevalences in the Western-European population (0.33-1.5\%). 
Newly diagnosed CD was only found in $0.19 \%$. We therefore believe that standard screening for CD in FLS patients is not recommended.

Author Contributions IdB performed the analysis, interpretation of data and prepared the first draft of the paper. LV, RvdV, SK, HJ, SW, and $\mathrm{JvdB}$ contributed to the acquisition of the data. FW, TT, JvdB, and PG contributed to the interpretation of data. $\mathrm{CW}$ contributed to the design of the work, the analysis and the interpretation of data. JvdB is the guarantor. All authors revised the paper critically for intellectual content and approved the final version. All authors agree to be accountable for the work and to ensure that any questions relating to the accuracy and integrity of the paper are investigated and properly resolved.

Funding Not applicable.

Data Availability Not applicable.

Code Availability Not applicable.

\section{Compliance with Ethical Standards}

Conflict of interest Dr. Janzing, Dr. Kaarsemaker, Dr. Trienekens, Dr. Vranken, Dr. van der Velde, Dr. Wyers, Dr. Wolters, and Dr. Wouda have nothing to disclose. Dr. de Bruin reports personal fees from Pfizer, personal fees from Novartis, personal fees from Sanofi, outside the submitted work; Dr. van den Bergh reports grants from Amgen, grants from Eli Lilly, grants from UCB, outside the submitted work; Dr. Geusens reports grants and personal fees from Amgen, grants from Pfizer, grants from MSD, grants from UCB, grants from Abbott, grants and personal fees from Lilly, grants from BMS, grants from Novartis, grants from Roche, grants from Will Pharma, outside the submitted work.

Ethical Approval Ethical approval was waived by the medical research ethics committee of the Academic Hospital Maastricht/University Maastricht (METC 2020-1508) in view of the retrospective nature of the study and all the procedures being performed were part of the routine care. The Dutch Medical Research Involving Human Subjects Act does not apply to our study. All procedures performed in studies involving human participants were in accordance with the ethical standards of the institutional and/or national research committee and with the 1964 Helsinki declaration and its later amendments or comparable ethical standards.

Informed Consent For this type of study formal consent is not required.

Open Access This article is licensed under a Creative Commons Attribution 4.0 International License, which permits use, sharing, adaptation, distribution and reproduction in any medium or format, as long as you give appropriate credit to the original author(s) and the source, provide a link to the Creative Commons licence, and indicate if changes were made. The images or other third party material in this article are included in the article's Creative Commons licence, unless indicated otherwise in a credit line to the material. If material is not included in the article's Creative Commons licence and your intended use is not permitted by statutory regulation or exceeds the permitted use, you will need to obtain permission directly from the copyright holder. To view a copy of this licence, visit http://creativecommons.org/licenses/by/4.0/.

\section{References}

1. Ludvigsson JF, Leffler DA, Bai JC et al (2013) The Oslo definitions for coeliac disease and related terms. Gut 62:43-52

2. Volta U, Caio G, Stanghellini V, De Giorgio R (2014) The changing clinical profile of celiac disease: a 15-year experience (19982012) in an Italian referral center. BMC Gastroenterol 14:194. https://doi.org/10.1186/s12876-014-0194-x

3. Zanchetta MB, Longobardi V, Bai JC (2016) Bone and celiac disease. Curr Osteoporos Rep 14:43-48. https://doi.org/10.1007/ s11914-016-0304-5

4. Olmos M, Antelo M, Vazquez H et al (2008) Systematic review and meta-analysis of observational studies on the prevalence of fractures in coeliac disease. Dig Liver Dis 40:46-53. https://doi. org/10.1016/j.dld.2007.09.006

5. Hjelle AM, Apalset E, Mielnik P et al (2014) Celiac disease and risk of fracture in adults-a review. Osteoporos Int 25:1667-1676. https://doi.org/10.1007/s00198-014-2683-8

6. Heikkilä K, Pearce J, Mäki M, Kaukinen K (2015) Celiac disease and bone fractures: a systematic review and meta-analysis. J Clin Endocrinol Metab 100:25-34. https://doi.org/10.1210/ jc. 2014-1858

7. Bianchi M-L, Bardella MT (2008) Bone in celiac disease. Osteoporos Int 19:1705-1716. https://doi.org/10.1007/s0019 8-008-0624-0

8. Xing Y, Morgan SL (2013) Celiac disease and metabolic bone disease. J Clin Densitom 16:439-444. https://doi.org/10.1016/j. jocd.2013.08.012

9. Fornari MC, Pedreira S, Niveloni S et al (1998) Pre- and posttreatment serum levels of cytokines IL-1beta, IL-6, and IL-1 receptor antagonist in celiac disease. Are they related to the associated osteopenia? Am J Gastroenterol 93:413-418. https://doi. org/10.1111/j.1572-0241.1998.00413.x

10. Grace-Farfaglia P (2015) Bones of contention: bone mineral density recovery in celiac disease-a systematic review. Nutrients 7:3347-3369. https://doi.org/10.3390/nu7053347

11. Sategna-Guidetti C, Grosso SB, Grosso S et al (2000) The effects of 1-year gluten withdrawal on bone mass, bone metabolism and nutritional status in newly-diagnosed adult coeliac disease patients. Aliment Pharmacol Ther 14:35-43

12. Kemppainen T, Kroger H, Janatuinen E et al (1999) Bone recovery after a gluten-free diet: a 5-year follow-up study. Bone 25:355360. https://doi.org/10.1016/s8756-3282(99)00171-4

13. Ludvigsson JF, Michaelsson K, Ekbom A, Montgomery SM (2007) Coeliac disease and the risk of fractures-a general population-based cohort study. Aliment Pharmacol Ther 25:273-285. https://doi.org/10.1111/j.1365-2036.2006.03203.x

14. Singh P, Arora A, Strand TA et al (2018) Global prevalence of celiac disease: systematic review and meta-analysis. Clin Gastroenterol Hepatol 16:823-836.e2. https://doi.org/10.1016/j. cgh.2017.06.037

15. Dubé C, Rostom A, Sy R et al (2005) The prevalence of celiac disease in average-risk and at-risk Western European populations: a systematic review. Gastroenterology 128:S57-S67. https://doi. org/10.1053/j.gastro.2005.02.014

16. Rostami K, Mulder CJ, Werre JM et al (1999) High prevalence of celiac disease in apparently healthy blood donors suggests a high prevalence of undiagnosed celiac disease in the Dutch population. Scand J Gastroenterol 34:276-279. https://doi.org/10.1080/00365 529950173681

17. Rios LP, Khan A, Sultan M et al (2013) Approach to diagnosing celiac disease in patients with low bone mineral density or fragility fractures: multidisciplinary task force report. Can Fam Physician 59:1055-1061 
18. Laszkowska M, Mahadev S, Sundström J et al (2018) Systematic review with meta-analysis: the prevalence of coeliac disease in patients with osteoporosis. Aliment Pharmacol Ther 48:590-597. https://doi.org/10.1111/apt.14911

19. McLellan AR, Gallacher SJ, Fraser M, McQuillian C (2003) The fracture liaison service: success of a program for the evaluation and management of patients with osteoporotic fracture. Osteoporos Int 14:1028-1034. https://doi.org/10.1007/s0019 8-003-1507-z

20. Åkesson K, Marsh D et al (2013) Capture the fracture: a best practice framework and global campaign to break the fragility fracture cycle. Osteoporos Int 24:2135-2152. https://doi.org/10.1007/ s00198-013-2348-z

21. Bours SPG, van Geel TACM, Geusens PPMM et al (2011) Contributors to secondary osteoporosis and metabolic bone diseases in patients presenting with a clinical fracture. J Clin Endocrinol Metab 96:1360-1367. https://doi.org/10.1210/jc.2010-2135

22. Bours SPG, van den Bergh JPW, van Geel TACM, Geusens PPMM (2014) Secondary osteoporosis and metabolic bone disease in patients 50 years and older with osteoporosis or with a recent clinical fracture: a clinical perspective. Curr Opin Rheumatol 26:430-439. https://doi.org/10.1097/BOR.0000000000000074

23. Geusens P, Bours SPG, Wyers CE, van den Bergh JP (2019) Fracture liaison programs. Best Pract Res Clin Rheumatol 33:278289. https://doi.org/10.1016/j.berh.2019.03.016

24. Malgo F, Appelman-Dijkstra NM, Termaat MF et al (2016) High prevalence of secondary factors for bone fragility in patients with a recent fracture independently of BMD. Arch Osteoporos 11:12. https://doi.org/10.1007/s11657-016-0258-3

25. Reumatologie NVV (2011) CBO richtlijn osteoporose en fractuurpreventie

26. Center JR, Bliuc D, Nguyen TV, Eisman JA (2007) Risk of subsequent fracture after low-trauma fracture in men and women. JAMA 297:387-394. https://doi.org/10.1001/jama.297.4.387

27. Kanis JA, Adachi JD, Cooper C et al (2013) Standardising the descriptive epidemiology of osteoporosis: recommendations from the Epidemiology and Quality of Life Working Group of IOF. Osteoporos Int 24:2763-2764

28. Genant HK, Wu CY, van Kuijk C, Nevitt MC (1993) Vertebral fracture assessment using a semiquantitative technique. J Bone Miner Res 8:1137-1148. https://doi.org/10.1002/jbmr.56500 80915

29. van Maag-Darm-Leverartsen NV (2008) Richtlijn Coeliakie en Dermatitis Herpetiformis

30. Rubio-Tapia A, Hill ID, Kelly CP et al (2013) ACG clinical guidelines: diagnosis and management of celiac disease. Am J Gastroenterol 108:656-676. https://doi.org/10.1038/ajg.2013.79

31. Pallav K, Xu H, Leffler DA et al (2016) Immunoglobulin A deficiency in celiac disease in the United States. J Gastroenterol Hepatol 31:133-137. https://doi.org/10.1111/jgh.13176

32. Marsh MN (1992) Gluten, major histocompatibility complex, and the small intestine. A molecular and immunobiologic approach to the spectrum of gluten sensitivity ("celiac sprue"). Gastroenterology 102:330-354

33. Oberhuber G, Granditsch G, Vogelsang H (1999) The histopathology of coeliac disease: time for a standardized report scheme for pathologists. Eur J Gastroenterol Hepatol 11:1185-1194. https:// doi.org/10.1097/00042737-199910000-00019

34. Ludvigsson JF, Bai JC, Biagi F et al (2014) Diagnosis and management of adult coeliac disease: guidelines from the British Society of Gastroenterology. Gut 63:1210-1228. https://doi. org/10.1136/gutjnl-2013-306578

35. Bai JC, Fried M, Corazza GR et al (2013) World Gastroenterology Organisation global guidelines on celiac disease. J Clin Gastroenterol 47:121-126. https://doi.org/10.1097/MCG.0b013e31827a6f8 3

36. Legroux-Gérot I, Leloire O, Blanckaert F et al (2009) Screening for celiac disease in patients with osteoporosis. Joint Bone Spine 76:162-165. https://doi.org/10.1016/j.jbspin.2008.06.016

37. Nuti R, Martini G, Valenti R et al (2001) Prevalence of undiagnosed coeliac syndrome in osteoporotic women. J Intern Med 250:361-366

38. González D, Sugai E, Gomez JC et al (2002) Is it necessary to screen for celiac disease in postmenopausal osteoporotic women? Calcif Tissue Int 71:141-144. https://doi.org/10.1007/s0022 3-001-1027-9

39. Hill PG, McMillan SA (2006) Anti-tissue transglutaminase antibodies and their role in the investigation of coeliac disease. Ann Clin Biochem 43:105-117. https://doi.org/10.1258/0004563067 76021599

40. Hjelle AM, Apalset E, Mielnik P et al (2018) Positive IgA against transglutaminase 2 in patients with distal radius and ankle fractures compared to community-based controls. Scand J Gastroenterol 53:1212-1216. https://doi.org/10.1080/00365 521.2018.1509122

41. Larussa T, Suraci E, Nazionale I et al (2012) Bone mineralization in celiac disease. Gastroenterol Res Pract 2012:198025-198029. https://doi.org/10.1155/2012/198025

42. Casella S, Zanini B, Lanzarotto F et al (2012) Celiac disease in elderly adults: clinical, serological, and histological characteristics and the effect of a gluten-free diet. J Am Geriatr Soc 60:1064 1069. https://doi.org/10.1111/j.1532-5415.2012.03997.x

43. Hudec SMD, Camacho PM (2013) Secondary causes of osteoporosis. Endocr Pract 19:120-128. https://doi.org/10.4158/EP120 59.RA

44. Croall ID, Trott N, Rej A et al (2019) A population survey of dietary attitudes towards gluten. Nutrients 11:1276. https://doi. org/10.3390/nu11061276

45. Kim H-S, Patel KG, Orosz E et al (2016) Time trends in the prevalence of celiac disease and gluten-free diet in the US population: results from the national health and nutrition examination surveys 2009-2014. JAMA Intern Med 176:1716-1717. https://doi. org/10.1001/jamainternmed.2016.5254

Publisher's Note Springer Nature remains neutral with regard to jurisdictional claims in published maps and institutional affiliations. 